\title{
Arterias y venas múltiples en injertos renales. Revisión de literatura sobre la anatomía y embriología en variantes vasculares renales y sobre los resultados en donación y trasplante de riñones con vascularidad múltiple
}

\author{
Multiple arteries and veins in kidney allografts. Literature review about \\ anatomy and embriology on renal vascular variations, and on the results \\ in donation and transplantation of kidneys with vascular multiplicity
}

\author{
Brian Rubio-Marín,* Carlos Alfonso Roca-Rodríguez,* \\ José Manuel Ramírez-Hernández ${ }^{\ddagger}$ \\ * Hospital Central Norte, PEMEX. \\ ₹ Hospital Central Norte, PEMEX. Unidad de Terapia Intensiva. \\ Coordinación Hospitalaria de Donación de Órganos y Tejidos, Ciudad de México, México.
}

\section{RESUMEN}

El incremento mundial en la incidencia de insuficiencia renal crónica ha generado una situación de mayor demanda de donación de riñones; esta demanda es superior al número de trasplantes renales que se realizan anualmente. Para lograr equilibrar estas cifras, es necesario el uso de injertos renales con criterios expandidos que provengan tanto de donantes vivos como de donantes fallecidos. Dentro de estos criterios expandidos, las variantes anatómicas toman particular relevancia por ser alteraciones originadas durante la embriogénesis, las cuales están presentes en aproximadamente $35 \%$ de la población; dentro de éstas, la presencia de arterias renales múltiples es la alteración vascular más común. Si bien, a partir de 2012, se dejó de considerar como contraindicación el uso de injertos renales con variantes anatómicas vasculares, debido a las innovaciones tecnológicas y al desarrollo de nue-

\section{ABSTRACT}

The worldwide increment in the incidence of chronic kidney disease has generated a situation with greater demand on kidney donation superior to the number of annual renal transplantations. For this reason, it's necessary the use of renal allograft from expanded criteria donors. In the expanded criteria, the renal anatomic variants have a particular relevancy for being alterations originated under the embriogenesis period, and for being present in approximately $35 \%$ of the population, with the presence of multiple renal arteries as the most common variant. Even thought in the year 2012 the use of kidney allografts with vascular multiplicity was no longer a contraindication, thanks to technological advancements and the development of new vascular reconstruction techniques that allow a higher safety in transplantation, with similar results as the transplantation of kidney allografts without multiple

Citar como: Rubio-Marín B, Roca-Rodríguez CA, Ramírez-Hernández JM. Arterias y venas múltiples en injertos renales. Revisión de literatura sobre la anatomía y embriología en variantes vasculares renales y sobre los resultados en donación y trasplante de riñones con vascularidad múltiple.

Rev Mex Traspl. 2020; 9 (3): 120-129. https://dx.doi.org/10.35366/97460 
vas técnicas quirúrgicas de reconstrucción vascular, las cuales permiten una mayor seguridad en el proceso de trasplante, además de contar con resultados similares a los trasplantes de injertos renales sin vascularidad múltiple, el manejo de los vasos múltiples en un injerto renal es todavía un reto técnico para el cirujano de trasplantes.

Palabras clave: Trasplante renal, venas renales, arterias renales, donación de órganos, supervivencia del injerto.

\section{INTRODUCCIÓN}

A nivel mundial, se estima un incremento en el número de pacientes con insuficiencia renal crónica terminal, cuya cifra aproximada es de 750 millones de personas, lo que equivale a $10 \%$ de la población mundial. ${ }^{1}$ Este incremento se asocia principalmente con dos factores que comparten una evolución hacia un proceso fibrótico renal: el aumento en la incidencia global de enfermedades crónico-degenerativas (entre las que destaca la diabetes mellitus tipo 2 y la hipertensión arterial) y un mayor diagnóstico de patologías glomerulares y estructurales que afectan predominantemente a la población pediátrica. ${ }^{2-4}$ Para el tratamiento de la insuficiencia renal crónica, se consideran dos líneas de manejo sustitutivo: temporal y definitivo. Aquellas temporales son: la diálisis peritoneal y hemodiálisis, y como manejo sustitutivo definitivo: el trasplante renal. ${ }^{5}$

En México, hasta 2019, se tiene registro de 17,069 pacientes ante el Centro Nacional de Trasplantes (CENATRA) en lista de espera de un trasplante renal. ${ }^{6} \mathrm{Si}$ bien, anualmente, se ha registrado un incremento en el número de trasplantes renales realizados en México, el incremento de los pacientes en lista de espera de riñón es superior a las cirugías realizadas. En este mismo año, se realizaron 2,939 trasplantes renales, lo que contrastó con los 15,072 receptores reportados al término del año 2018.7,8

Debido a esta disparidad, es necesaria una optimización en la relación donación-trasplantes renales, por ejemplo, mediante modificaciones en las políticas de salud, como las implementadas a nivel mundial por la Organización Mundial de la Salud (OMS). Estas modificaciones han permitido aumentar el número de donantes vivos de riñón ${ }^{2}$ y tener una mayor aceptación de injertos renales provenientes de donantes con criterios expandidos, como son la aceptación de órganos provenientes de donantes con parada cardiaca (categoría Maastricht III) y el uso de injertos renales con variantes anatómicas. . $^{3,9}$

Existen diversas variantes anatómicas en los riñones, las más comunes son las que afectan al sistema vascularity; the management of renal allografts with multiple vascularity is still a major challenge for the surgeon.

Keywords: Kidney transplantation, renal veins, renal arteries, organ donation, allograft survival.

colector y las ubicadas en el sistema vascular; éstas son las más frecuentes, pues se ha reportado que presentan en $35 \%$ de los casos..$^{5,10}$ De estas variantes vasculares, la más común es la presencia de arterias renales múltiples, al tener una incidencia de manera unilateral en 18 a $30 \%$ de la población, ${ }^{11,12}$ y bilateral en $15 \%$ de los casos (Figura 1). ${ }^{12}$

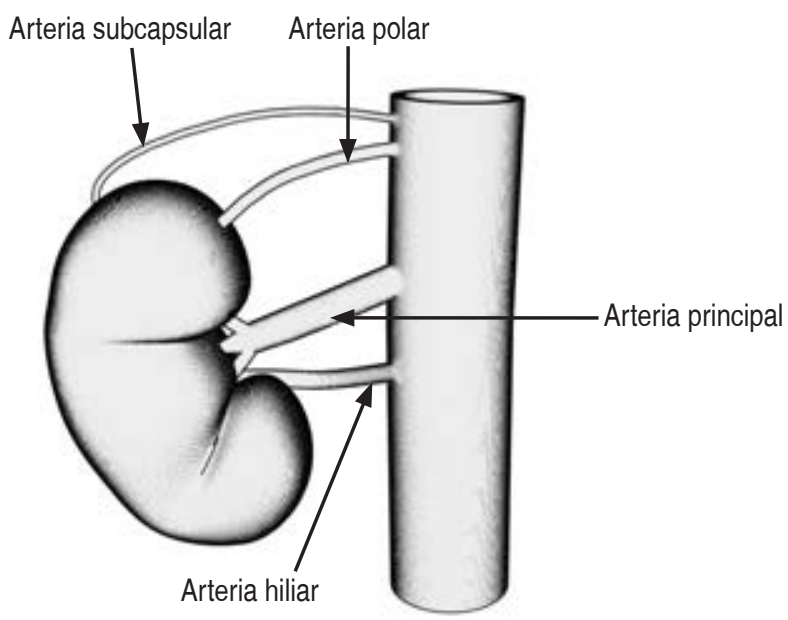

Figura 1: Principales variantes anatómicas de las arterias renales. Estas variantes se originan durante la embriogénesis debido a que no se presenta una involución de los brotes arteriales que irrigan a los riñones embriogénicos durante su ascenso a la posición lumbar definitiva. llustración: Miguel Federico Rubio Marín.

Si bien, hace algunos años el hallazgo de variantes vasculares se consideraba como una contraindicación en algunos centros de trasplante, esta situación cambió a partir de 2012 con la estandarización de novedosas tecnologías y el avance en técnicas quirúrgicas de reconstrucción vascular, las cuales han permitido obtener mejores resultados de injertos con anatomía vascular múltiple, lo cual ha sido equiparable a los resultados obtenidos con injertos renales de vasculatura convencional. ${ }^{12,13}$ 
Pese a estos resultados favorables, el uso de injertos complejos representa aún un gran reto técnico para el cirujano de trasplantes, quien no está exento de complicaciones que modifiquen el funcionamiento y supervivencia del injerto. Durante el transoperatorio, las complicaciones más comúnmente asociadas con el uso de estos injertos son: mayor tiempo quirúrgico requerido para la reparación vascular y mayor riesgo elevado de sangrado. ${ }^{5,11}$ En el postoperatorio, las posibles complicaciones que se pueden presentar son: un tiempo de hospitalización prolongado, la infección de la herida quirúrgica y el retraso en la función del injerto, lo que puede inducir a la necesidad de un reemplazo renal mediante hemodiálisis. ${ }^{5}$

\section{Anatomía vascular renal}

Anatomía arterial renal convencional: Cada riñón es irrigado por una sola arteria renal que se origina desde la cara lateral de la aorta abdominal, habitualmente por debajo del origen de la arteria mesentérica superior al nivel de la primera vértebra lumbar; esta arteria sigue un trayecto oblicuo, hacia abajo y posterolateral, y la arteria derecha es de mayor longitud que la izquierda. ${ }^{14,15} \mathrm{~A}$ nivel del hilio, cada arteria renal se divide en sus dos ramas terminales: la arteria prepiélica y la arteria retropiélica; a su vez, éstas se dividen en arterias segmentarias. ${ }^{14,16} \mathrm{Al}$ no presentarse una anastomosis entre estas ramas de la arteria renal, cada arteria tiene un territorio de irrigación específico, lo que permite hacer una división en segmentos anatómicos independientes: esto es, dos segmentos polares, superior e inferior, que reciben irrigación de las arterias polares superior e inferior, respectivamente; tres segmentos mesorrenales, es decir, anterosuperior y anteroinferior, cuyas arterias nacen de la arteria prepiélica, y el segmento posterior, el cual es irrigado directamente por la arteria retropiélica. ${ }^{16,17}$

Variantes arteriales: Estas variantes anatómicas se originan entre la sexta y novena semana de gestación con el ascenso embriológico de los riñones, los cuales se ubican originalmente en una posición pélvica, a nivel sacro. A partir de la sexta semana de gestación, los riñones embriogénicos tienen un proceso de ascenso, cuyo trayecto es paralelo a la aorta dorsal, el cual finaliza cuando los riñones llegan a una posición lumbar por debajo de las glándulas suprarrenales. ${ }^{18} \mathrm{~A}$ medida que se da el ascenso renal, se va generando una vasculatura temporal proporcionada por diversos brotes arteriales que involucionan conforme se va dando el ascenso renal, y que procede inicialmente de la arteria iliaca común; posteriormente, de la porción distal de la zona terminal de la aorta $y$, finalmente, de la aorta abdominal al momento de entrar en contacto con la glándula suprarrenal, con lo cual desaparece la arteria renal embriogénica y se sustituye por la arteria renal permanente, que proviene de la aorta abdominal. ${ }^{18,19}$ No obstante, estos brotes arteriales no siempre involucionan, persistiendo como arterias renales accesorias. ${ }^{18}$ Habitualmente, la arteria mesentérica superior es el punto de origen más alto de una arteria renal accesoria, aunque hay reportes de arterias renales accesorias originadas en la porción cefálica del tronco celiaco. Dicha situación se presenta cuando el riñón se encuentra en una posición cefálica anormal. ${ }^{20}$ En cuanto al origen inferior de arterias accesorias renales, se originan a nivel de la aorta inferior, aunque, en ocasiones, se pueden originar de la arteria iliaca común ipsilateral. ${ }^{17,20} \mathrm{En}$ muy raras ocasiones, se puede dar un aporte arterial proveniente de la arteria mesentérica inferior, o un aporte proveniente de la arteria renal contralateral. ${ }^{20}$

Anatomía venosa renal convencional: El drenaje renal está dado por las venas renales y los vasos sanguíneos con un trayecto anterior a las arterias renales. ${ }^{17,21}$ El drenaje venoso está dado secuencialmente por la vena interlobular, arcuata, interlobar y lobar, las cuales convergen para formar la vena renal principal. ${ }^{17}$ Del lado derecho, esta vena renal drena directamente en la cara lateral de la vena cava inferior, y del lado izquierdo, la vena renal atraviesa entre la arteria mesentérica superior y la aorta antes de drenar en la cara medial de la vena cava inferior, por lo que esta vena tiene una longitud tres veces mayor a la de la vena renal derecha. ${ }^{15,17,21}$

Variantes venosas: Las variantes venosas a nivel renal se asocian con las venas cardinales, un grupo de venas que participan en el desarrollo de la vena cava y que, junto con el conjunto de venas umbilicales y vitelinas, forman el sistema venoso embrionario. ${ }^{20,21}$ En la tercera semana de gestación, existe un par de venas cardinales anteriores que drenan la porción cefálica del embrión, y un par de venas cardinales inferiores que drenan al resto del cuerpo. ${ }^{20}$ Posteriormente, durante la quinta semana de gestación, se desarrollan las venas supracardinales, sacrocardinales y subcardinales; estas últimas tienen la función del drenaje sanguíneo del mesonefros. Entre las venas subcardinales se da una serie de anastomosis transversas, lo que da lugar a la formación de la vena renal izquierda y a la desaparición de la vena subcardinal izquierda, persistiendo solamente su porción distal, la cual se convierte en la 
vena gonadal izquierda. La vena subcardinal derecha también involuciona, persistiendo una porción que se convierte en el segmento renal de la vena cava inferior, y una porción que se convierte en la vena renal derecha. ${ }^{20,21}$ A su vez, las venas supracardinales establecen anastomosis entre sí y con las venas subcardinales a través de la anastomosis subcardino-supracardinal. Esta anastomosis de lado izquierdo contribuye a formar la vena renal izquierda; esta misma, del lado derecho, participa en la formación del segmento renal de la vena cava inferior. ${ }^{22}$ Las alteraciones durante el desarrollo del mesonefros, así como la persistencia de elementos embriológicos, se traducen en múltiples anormalidades venosas renales, siendo la más común la presencia de venas renales supernumerarias a nivel derecho, la cual está en 15 a 30\% de los individuos. ${ }^{17,20}$ Esta situación se presenta a nivel izquierdo en $3 \%$ de la población..$^{20}$ La vena renal izquierda habitualmente presenta anomalías en el trayecto, y la más común de éstas es la presencia de un collar venoso renal. Dicha anomalía se debe a la persistencia de segmentos de las anastomosis subcardinales y supracardinales..$^{20,23}$ Otras anomalías del trayecto son la vena renal retroaórtica y la vena renal retroaórtica oblicua. ${ }^{17,20} \mathrm{Fi}$ nalmente, en menor medida, puede presentarse una doble vena cava inferior (Figura 2). ${ }^{20}$
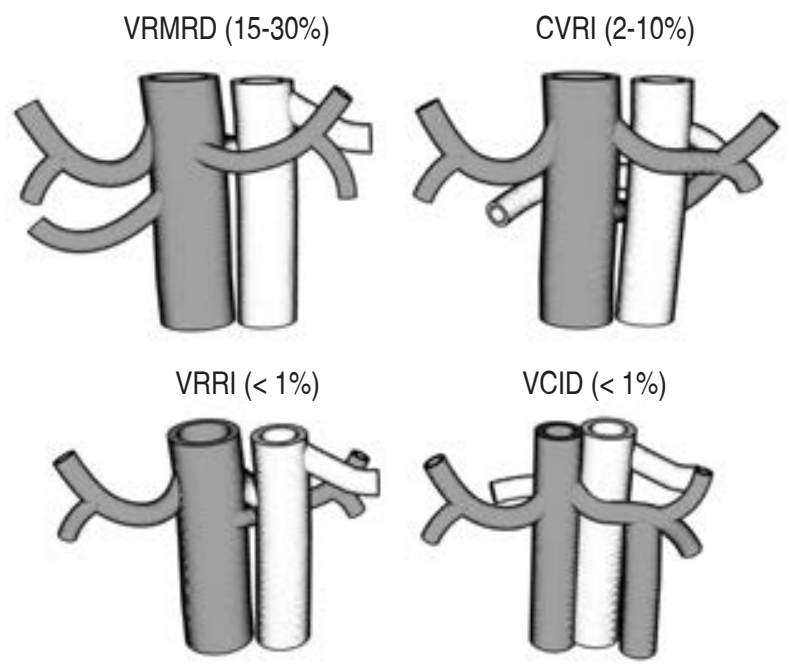

VRMRD = venas renales múltiples en riñón derecho, $C V R I=$ collar venoso renal izquierdo, VRRI = vena renal retroaórtica izquierda, $\mathrm{VCID}$ = vena cava inferior duplicada.

Figura 2: Principales variantes anatómicas de las venas renales. Las alteraciones en el desarrollo del mesonefros y la persistencia de elementos embriológicos del sistema venoso embrionario se traducen en múltiples anormalidades venosas renales.

llustración: Miguel Federico Rubio Marín.

\section{Extracción de riñones con variantes vasculares}

Los primeros estudios realizados sobre el impacto de las variantes vasculares renales consideraban como una contraindicación el uso de injertos con arterias renales múltiples, debido a un posible aumento en las complicaciones vasculares, como son la estenosis, trombosis de la arteria renal y el sangrado, así como por la necesidad de realizar la anastomosis de las arterias accesorias. Este procedimiento técnicamente demandante puede prolongar el tiempo de isquemia caliente, lo que se traduce en un aumento en la incidencia de necrosis tubular aguda, así como en el retardo en la función del injerto. ${ }^{12,23}$ Sin embargo, a partir de 2012, los avances tecnológicos y la estandarización de técnicas quirúrgicas en reconstrucción vascular, así como la realización de estudios de imagen al donante vivo como parte del protocolo previo a la donación, han permitido minimizar el riesgo de complicaciones durante el trasplante, tanto para el receptor como para el donante vivo. ${ }^{11-13,24}$

La angiotomografía renal ha adquirido relevancia al ser un método mínimamente invasivo con la ventaja de que permite observar la presencia de patologías intrínsecas del riñón, como masas renales, calcificaciones, litiasis y alteraciones del sistema excretor; 25,26 asimismo, ha permitido definir la arquitectura vascular renal, al evaluar el número y localización de arterias y venas principales y el patrón de ramas vasculares accesorias. ${ }^{25}$ La angiotomografía renal tiene una sensibilidad de $88 \%$ y una especificidad de $98 \%$ para identificar arterias renales accesorias; para identificar ramas arteriales prehiliares, tiene una sensibilidad de $100 \%$ y una especificidad de 97\%; finalmente, para identificar anomalías venosas, cuenta con una sensibilidad de $100 \%$ y una especificidad de $97 \%$. Por este motivo, se considera el estudio de elección para la evaluación preoperatoria del donante (Figuras 3 y 4). ${ }^{27}$

En cuanto a la nefrectomía, en caso de un donante vivo, la estandarización de la técnica laparoscópica ha permitido obtener mejores resultados para la seguridad del donante, en términos de pérdidas sanguíneas se traduce en menores requerimientos transfusionales, anestésicos y menor tiempo de hospitalización. ${ }^{12,24,25,28}$ Para tener un mejor resultado durante la laparoscopia, se recomienda obtener el riñón izquierdo, debido a que se tiene un acceso transperitoneal más sencillo al no haber presencia de estructuras anatómicas que compliquen la disección ${ }^{24}$ y por la mayor longitud de la vena renal izquierda, lo que permite una mayor maniobra durante el trasplante..$^{24,29}$ 


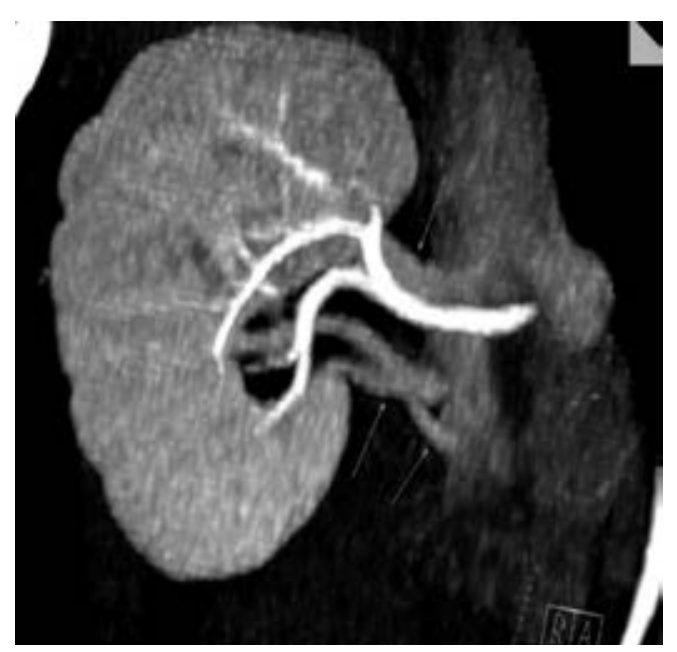

Figura 3: Imagen obtenida por angiotomografía en fase arterial, en la cual se observa un corte coronal de riñón derecho, con presencia de tres venas renales que drenan a la vena cava por separado.

Tomado de: Ikidag MA et al. ${ }^{26}$

En el metaanálisis de 24 estudios comparativos publicados entre 1970 y 2016, realizado por Afriansyah y colaboradores, ${ }^{24}$ y en la revisión retrospectiva de 951 trasplantes renales llevada a cabo por Lafranca y colaboradores ${ }^{30}$ se analizaron los resultados obtenidos en la extracción de injertos renales de vasculatura convencional en donantes vivos, los cuales se compararon con la extracción de injertos renales complejos con variantes vasculares. Los resultados se descritos fueron similares para la procuración de ambos tipos de injertos renales.

En lo referente al tiempo total empleado durante el procedimiento quirúrgico de procuración, se considera un promedio de 188 minutos en la obtención de injertos renales con una vasculatura convencional. ${ }^{24} \mathrm{En}$ injertos con arterias múltiples, el tiempo promedio de procuración es de 214 minutos, y de 203 minutos en riñones con venas múltiples. ${ }^{24,30}$

En cuanto al primer tiempo de isquemia caliente, se considera una duración de cuatro minutos en la obtención de injertos renales sin variantes vasculares, y un tiempo que oscila entre los cuatro minutos y medio a los cinco minutos en riñones con arterias o venas múltiples. 24,30

Si bien, durante el proceso de procuración en caso de donantes vivos, el sangrado que se presenta en el transoperatorio es variable. Se considera un sangrado promedio de 151 mililitros en el caso de donación de riñones con una anatomía vascular normal. En las variantes anatómicas, el sangrado promedio es de 207 mililitros en injertos con múltiples arterias, y de 168 mililitros en la obtención de riñones con venas múltiples. ${ }^{24,30}$

Durante la procuración, las complicaciones en el transoperatorio tienen una baja incidencia. Así, en los resultados descritos por Afriansyah, se presentan en un $6.3 \%$ de los donantes de un injerto renal de vasculatura convencional, y en un $6.4 \%$ en donantes de injertos con arterias múltiples (Tabla 1). ${ }^{24}$ Lafranca, por su parte, reporta una incidencia de complicaciones de $8.4 \%$ en

Tabla 1: Resultados obtenidos en el uso de injertos renales con vasculatura múltiple comparados con el uso de riñones sin variantes vasculares.

\begin{tabular}{lcc}
\hline & & Donación renal \\
\cline { 2 - 3 } & Donantes con arteria renal única & Donantes con arterias renales múltiples \\
\hline Tiempo de cirugía (minutos) & 188 & 214 \\
Isquemia caliente (segundos) & 265 & 238 \\
Pérdida sanguínea estimada (militros) & 175.06 & 214.11 \\
Incidencia de complicaciones (\%) & 6.3 & 6.4 \\
& & Trasplante renal \\
& & Arterias renales múltiples \\
\hline Segundo tiempo de isquemia caliente (minutos) & Arteria renal única & 30 \\
Tiempo de isquemia fría (minutos) & 28 & 79 \\
Incidencia de complicaciones vasculares (\%) & 67 & 2.6 \\
Incidencia de complicaciones ureterales (\%) & 1.3 & 3.5 \\
Retraso en la función renal (\%) & 2.7 & 5.1 \\
Supervivencia del injerto al primer año (\%) & 5.2 & 93.0 \\
\hline
\end{tabular}

Tomado de: Afriansyah et al..$^{24}$ 


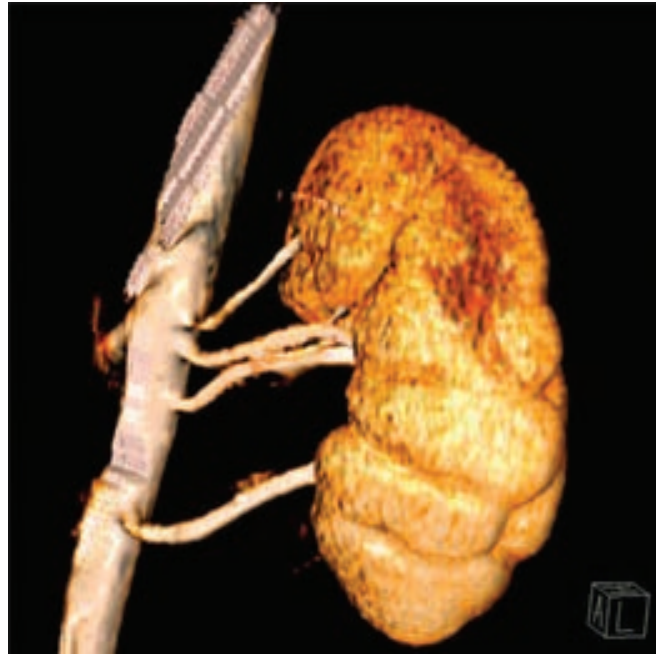

Figura 4: Reconstrucción en 3D de riñón izquierdo. Se observan cuatro segmentos arteriales separados, originados de la aorta. Dos de los segmentos atraviesan el hilio renal, uno el polo superior y otro el polo inferior del riñón izquierdo.

Tomado de: Ikidag MA et al. ${ }^{26}$

donantes de un injerto renal de vasculatura convencional; este resultado contrasta con una la incidencia reportada de $10.1 \%$ en donantes de un riñón con arterias múltiples, y la incidencia del $17.2 \%$ en donantes de un injerto con venas múltiples (Tabla 2 ). ${ }^{30}$
Durante la estancia hospitalaria postoperatoria del donante, las principales complicaciones son las infecciones y hematomas de la incisión de Pfannestiel, así como la retención urinaria. ${ }^{30}$ Para estadificar las complicaciones de manera cualitativa, se usa la clasificación de Clavien-Dindo. ${ }^{24,28,31}$ Con esta clasificación, el porcentaje de complicaciones postquirúrgicas en los donantes de un injerto con vasculatura convencional se divide en: grado I en un $10 \%$; grado II en $8 \%$; grado III en $7 \%$, y grado IV en $0.3 \%$. Cuando se realiza la comparación con las complicaciones postquirúrgicas en los donantes vivos de un injerto con vasculatura múltiple, éstas se dividen en: grado I en $6 \%$; grado II en $11 \%$; grado III en $9 \%$, y grado IV en $0.8 \% .{ }^{28}$

\section{TRASPLANTE DE RIÑONES CON VARIANTES VASCULARES}

Los resultados recopilados tanto por el equipo de Afriansyah ${ }^{24}$ como por el equipo de Lafranca ${ }^{30}$ muestran una similitud entre el trasplante de un injerto renal con anatomía vascular convencional y el trasplante de un injerto renal con vasculatura compleja. El tiempo total empleado para el proceso de trasplante es, en promedio, en el caso de trasplante de un injerto renal de vasculatura convencional, de 132 minutos; para el uso de injertos con arterias renales múltiples este tiempo es de 135 minutos, y cuando se

Tabla 2: Resultados obtenidos en el uso de injertos renales con vasculatura múltiple comparados con el uso de riñones sin variantes vasculares.

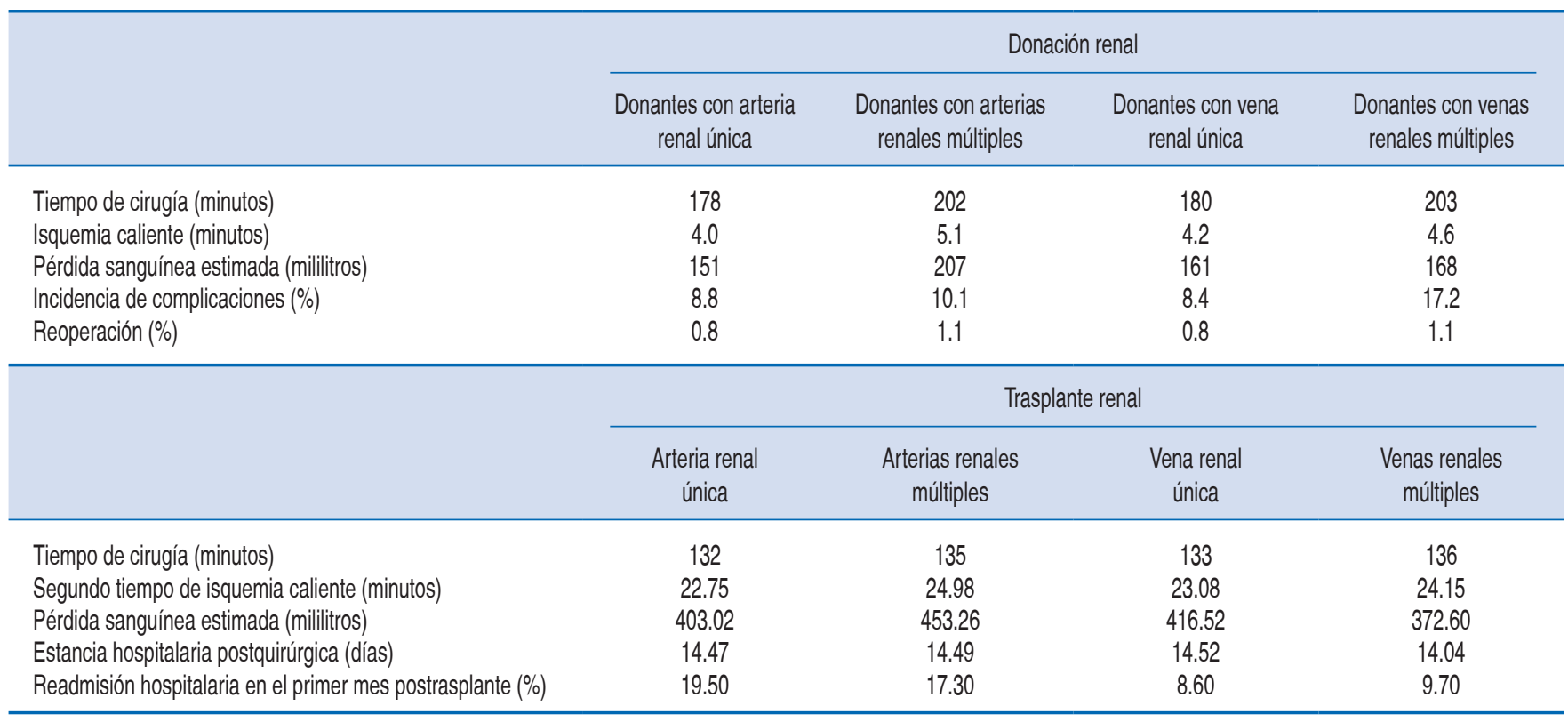

Tomado de: Lafranca et al.30 
trata de un injerto con venas renales múltiples es de 136 minutos. ${ }^{30}$

En el trasplante renal, un aspecto de suma importancia es el tiempo de isquemia fría durante el cual se realiza la preparación del injerto y la reconstrucción vascular cuando el injerto presenta variantes en la vasculatura. Este tiempo, conocido como cirugía de ban$\mathrm{co},{ }^{32}$ tiene una duración de 67 minutos cuando se trata de injertos renales con una vasculatura convencional, y de 79 minutos cuando se trata de un injerto que requiere una reconstrucción vascular. ${ }^{24}$ Cabe mencionar que el tiempo de isquemia fría requerido durante la cirugía de banco presenta una variación en relación con la técnica que se utilice para la reconstrucción vascular de los injertos con una variante vascular. ${ }^{33}$

El tiempo requerido durante el segundo periodo de isquemia caliente va de los 23 a 28 minutos en trasplantes de injertos renales sin alteraciones vasculares. En el trasplante de injerto renal con múltiples arterias renales, se considera un tiempo entre los 25 y 30 minutos..$^{24,30}$ El segundo tiempo de isquemia caliente usando injertos con múltiples venas renales es, en promedio, de 24 minutos. ${ }^{30}$

Al igual que en el proceso de procuración, el sangrado que se presenta durante el transoperatorio es dependiente de las situaciones propias de cada trasplante. Se puede considerar un sangrado promedio de 403 mililitros durante el tiempo quirúrgico, al tratarse de un trasplante renal con una vasculatura convencional. En trasplantes de injertos con vasculatura múltiple, se considera un sangrado promedio de 453 mililitros en riñones con arterias múltiples, y de 372 mililitros al tratarse de un injerto con más de una vena. ${ }^{30}$

En cuanto a las complicaciones postoperatorias, Zorgdrager reportó una incidencia de complicaciones de $11 \%$ en trasplantados de injertos renales con vasculatura convencional, y de $13.8 \%$ en receptores de injertos con anatomía vascular múltiple. ${ }^{33}$

De estas complicaciones, las más comunes son las urológicas, seguidas de aquéllas que afectan a la vasculatura arterial y de las complicaciones en la herida quirúrgica. ${ }^{24,34,35}$ Estas complicaciones pueden generar un retraso en la función renal del injerto, lo que puede conllevar a una disfunción renal, pérdida del injerto o la muerte del paciente trasplantado. ${ }^{23}$ En cuanto al retraso en la función renal, definido como el requerimiento de diálisis en la primera semana postrasplante, ${ }^{36}$ la incidencia es similar, tanto en pacientes receptores de un injerto con vasculatura convencional como en pacientes receptores de un injerto con vasculatura múltiple, cuyo retraso oscila entre 5.2 y $5.1 \%$ en los pacientes, respectivamente. ${ }^{24}$

La supervivencia al primer año de los pacientes receptores, tanto de injertos sin anormalidades vasculares como de injertos con una vasculatura múltiple, es de $93 \% .^{33}$ En cuanto a la supervivencia de los injertos renales sin anormalidades vasculares al primer año, ésta es de $95 . \%$, con un nivel promedio de creatinina de 1.38 $\mathrm{mg} / \mathrm{dL}$. En el caso de los injertos con arterias múltiples, la supervivencia es de $93 \%$, con una cifra promedio de creatinina de $1.44 \mathrm{mg} / \mathrm{dL} .{ }^{24,33}$ A los cinco años, la supervivencia de los pacientes que recibieron un injerto de vasculatura convencional es de $87 \%$; en tanto que los pacientes receptores de un injerto con vasculatura múltiple tienen una supervivencia de $89.6 \% .^{33}$ Los injertos con una vasculatura sin anormalidades tienen una supervivencia a los cinco años de $81.6 \%$, con un valor de creatinina promedio de $1.55 \mathrm{mg} / \mathrm{dL}$, mientras que la supervivencia de los injertos con vasculatura múltiples es de $81.4 \%$, manteniendo un nivel de creatinina promedio de $1.72 \mathrm{mg} / \mathrm{dL}$ (Tabla 3). ${ }^{24,33}$

\section{DISCUSIÓN}

La variante anatómica renal más común es la presencia de arterias múltiples. Ésta se observa de 18 a 30\% en la población.11,12 Se ha identificado que esta variante vascular está presente en el riñón derecho hasta en $90 \%$ de los casos de multiplicidad arterial. ${ }^{12,14}$ Por este motivo, y debido a una mayor longitud de la vena

Tabla 3: Supervivencia del receptor y del injerto renal al año y a los cinco años.

\begin{tabular}{|c|c|c|c|c|c|c|}
\hline \multirow[b]{2}{*}{ Supervivencia } & \multirow[b]{2}{*}{$\begin{array}{c}\text { Receptor de injerto con } \\
\text { vasculatura convencional }(\%)^{5}\end{array}$} & \multicolumn{2}{|c|}{$\begin{array}{l}\text { Injerto de vasculatura } \\
\text { convencional }\end{array}$} & \multirow[b]{2}{*}{$\begin{array}{l}\text { Receptor de injerto con } \\
\text { vasculatura múltiple }(\%)^{5}\end{array}$} & \multicolumn{2}{|c|}{$\begin{array}{l}\text { Injerto de vasculatura } \\
\text { múltiple }\end{array}$} \\
\hline & & $(\%)$ & Creatinina $(\mathrm{mg} / \mathrm{dL})^{1,5}$ & & $(\%)$ & Creatinina $(\mathrm{mg} / \mathrm{dL})^{1,5}$ \\
\hline A un año & 95.4 & $94.5-95.3$ & 1.38 & 95.4 & 93 & 1.44 \\
\hline A cinco años & 87.0 & 81.6 & 1.55 & 89.6 & 81.4 & 1.72 \\
\hline
\end{tabular}


renal izquierda respecto a la derecha, la mayoría de los cirujanos de trasplantes prefieren el uso de injertos renales izquierdos. . $^{2,18,24,28,29,31}$

En la actualidad, como parte del protocolo realizado a todo donador vivo previo a la cirugía, se realiza una angiotomografía renal. Este método de imagen permite visualizar la presencia de patologías intrínsecas de los riñones del donante vivo, y de igual modo sirve para definir la anatomía vascular renal. ${ }^{25}$ Debido a su alta sensibilidad y especificidad para identificar arterias y venas múltiples, la angiotomografía permite que se conozcan todas las variantes anatómicas de un injerto renal proveniente de un donante vivo, previo a la nefrectomía y al trasplante en el receptor. ${ }^{27}$

En la literatura, se reporta que el uso de injertos renales con anatomía vascular múltiple no representa una contraindicación. Afriansyah y colaboradores reportaron en un metaanálisis de 24 estudios comparativos que en la extracción renal de donante vivo no hay diferencia significativa en la estancia hospitalaria, en las pérdidas sanguíneas transoperatorias y en la duración del proceso quirúrgico y tiempos de isquemia, así como en las complicaciones que afectan al donador, comparando la extracción de riñones con arterias múltiples, con la procuración de injertos con arteria única. No obstante, se describe un incremento en el riesgo de pérdida de la función del injerto renal al primer año postrasplante, y un aumento en las complicaciones vasculares y ureterales en los receptores de un injerto con arterias o venas múltiples. ${ }^{24}$

Lafranca y colaboradores, en su revisión retrospectiva de 951 trasplantes renales, reportaron un total de 237 casos (25\%), en los cuales hubo presencia de venas o arterias renales múltiples. En estos casos de anatomía vascular múltiple, se registraron resultados similares respecto a la procuración de un riñón con arteria única, con diferencia no significativa en el impacto clínico transoperatorio y postoperatorio para el donante vivo. Cabe resaltar que en la obtención de riñones con venas múltiples, los resultados presentaron una diferencia en la incidencia de complicaciones en el donante, siendo de $17.2 \%$ en los donantes de injerto renal con venas múltiples, y de $8.4 \%$ en los donantes de riñón con vena única. Otra diferencia reportada de interés clínico que afecta al receptor en esta revisión es la incidencia en el retraso de la función renal del injerto, siendo de $13.9 \%$ en receptores de injerto con vasculatura múltiple, y de $6.9 \%$ en los receptores de riñón sin estas variantes vasculares. ${ }^{30}$

En la reconstrucción vascular de los injertos con vasos múltiples, existen diversas opciones, siendo las más utilizadas en injertos con arterias múltiples la anastomosis latero-lateral entre dos arterias, la anastomosis término-lateral de una arteria menor a una arteria principal, o bien la combinación de estas dos técnicas, así como la ligadura de la arteria polar superior y el parche aórtico de Carrel cuando el injerto proviene de un donante fallecido. ${ }^{23,28,32,37} \mathrm{En}$ injertos que requieren una reconstrucción de la vena renal, se realiza la ligadura de colaterales, y el alargamiento con parche de vena cava cuando se utiliza un injerto renal derecho. ${ }^{32}$ El éxito de la reconstrucción vascular renal disminuye la incidencia de complicaciones en el receptor y evita un retraso en la función renal del injerto, así como una menor supervivencia del injerto. ${ }^{23,37}$

Dentro de la reconstrucción vascular, el desarrollo de nuevas técnicas microquirúrgicas ha mostrado un gran beneficio en el trasplante renal, ya que por medio de ellas se logra obtener un aumento del aporte sanguíneo en el injerto, lo que eventualmente previene la necrosis del tejido. Dentro de estas técnicas, destacan el supercharging, que consiste en una anastomosis directa de la arteria renal accesoria con otro vaso sanguíneo (siendo la porción proximal de la arteria epigástrica inferior ipsilateral la más usada), y el turbocharging, una técnica en la cual se realiza una anastomosis entre la arteria renal y la arteria renal accesoria mediante un autoinjerto vascular, obtenido generalmente de la arteria epigástrica inferior profunda. En 2017, Jeong y colaboradores describieron el caso de dos pacientes que recibieron un injerto renal con arterias múltiples, y en quienes se usó, a manera de anastomosis microvascular, la técnica de supercharging y turbocharging, respectivamente. En ambos pacientes, se obtuvo una adecuada perfusión del injerto confirmada por ultrasonografía Doppler, sin que presentaran complicaciones transoperatorias y postoperatorias ni rechazo del injerto. ${ }^{37}$ No obstante, al ser una técnica de reciente aplicación al trasplante renal, no se cuenta con los estudios suficientes para definir la mejor eficacia de una u otra técnica en el trasplante de riñones con anatomía vascular múltiple.

En conclusión, con una adecuada técnica quirúrgica, el uso de injertos renales con anatomía vascular múltiple ha reportado resultados similares a los obtenidos cuando se usan injertos con vascularidad convencional. No obstante, el manejo de estos injertos con vasos múltiples continúa representando un gran reto técnico. Para lograr superar esta dificultad, es necesario que el cirujano de trasplantes conozca todas las técnicas de reconstrucción vascular y microquirúrgicas, ya que con ellas se evitará el descarte 
de un potencial donante que presente variantes vasculares en su riñones; de igual manera, debe conocer las complicaciones que puedan generar una disminución en la supervivencia tanto de los pacientes como del injerto.

\section{REFERENCIAS}

1. Crews DC, Bello AK, Saadi G. 2019 World kidney day editorial - burden, access, and disparities in kidney disease. J Bras Nephrol. 2019; 41 (1): 1-9.

2. Vasyutina E, Treier M. Molecular mechanisms in renal degenerative disease. Sem Cell Dev Biol. 2010; 21 (8): 831-837.

3. García-García G, Harden P, Chapman J. El papel global del trasplante renal. Nefrología. 2012; 32 (1): 1-6.

4. Becherucci F, Roperto RM, Materassi M, Romagnani P. Chronic kidney disease in children. Clinl Kidney J. 2016; 9 (4): 583-591.

5. Hernández-Rivera JC, Espinoza-Pérez R, Cancino-López JD, Silva-Rueda RI, Salazar-Mendoza M, Paniagua-Sierra R. Anatomical variants in renal transplantation, surgical management, and impact on graft functionality. Transplant Proc. 2018; 50 (10): 3216-3221.

6. Centro Nacional de Trasplantes [web]. Estado Actual de Receptores, Donación y Trasplantes en México, 20. Semestre 2019. Disponible en: https://www.gob.mx/cms/uploads/ attachment/file/529919/2doSemestre2019.pdf

7. Centro Nacional de Trasplantes [web]. Reporte Anual 2019 de Donación y Trasplantes en México. Secretaría de Salud. Disponible en: https://www.gob.mx/cms/uploads/attachment/ file/528301/Presentacion_anual_2019.pdf

8. Centro Nacional de Trasplantes [web]. Reporte Anual 2018 de Donación y Trasplantes en México. Secretaría de Salud. Disponible en: https://www.gob.mx/cms/uploads/attachment/ file/427652/Presentacion_anual_2018.pdf

9. Wu DA, Oniscu GC. Principles of organ donation and general surgery in the transplant patient. En: Paterson-Brown S, Paterson HM (ed.). Core topics in general and emergency surgery. 6a. ed. Edinburgh: Elsevier Ltd; 2019, pp. 122-134.

10. Ferreira $\mathrm{AH}$. Variaciones anatómicas bilaterales de vasos renales y testiculares. Rev CES Med. 2014; 28 (2): 273-282.

11. Kwapisz M, Kieszek R, Bieniasz $M$, Jędrzejko K, Nita $M$, Sulkowsk $\mathrm{K}$ et al. Do anatomical anomalies affect the results of living donor kidney transplantation? Transplant Proc. 2018; 50 (6): 1669-1673.

12. Hung CJ, Lin YJ, Chang SS, Chou TC, Lee PC. Kidney grafts with multiple renal arteries is no longer a relative contraindication with advance in surgical techniques of laparoscopic donor nephrectomy. Transplant Proc. 2012; 44: 36-38.

13. Bozkurt B, Koçak H, Dumlu EG, Mesci A, Bahadir V, Tokaç M et al. Favorable outcome of renal grafts with multiple arteries: a series of 198 patients. Transplant Proc. 2013; 45: 901-903.

14. Méndez LV, Casado MP, López LR, Ferrer MC, Trevín FG, Méndez JO. Variantes anatómicas de las arterias polares del riñón. Rev Med Electrón. 2014; 36(1): 720-728.

15. Berns JS. Vascular disorders of the kidney. In: Benjamin IJ, Griggs RC, Wing EJ (ed). Andreoli and Carpenter's Cecil essentials of medicine, 9a. ed. Philadelphia: Elsevier Saunders; 2016, pp. 341-351.

16. Lavorato N. Análisis de la distribución intraparenquimatosa de la arteria renal. Revista Argentina Anatomía Online. 2017; 8 (2): 58-64.
17. Hazırolan T, Öz M, Türkbey B, Devrim KA, Sayan OB, Canyiğit $M$. CT angiography of the renal arteries and veins: Normal anatomy and variants. Diagn Interv Radiol. 2011; 17 (1): 67-73.

18. Cruzat C, Olave E. Irrigación renal: multiplicidad de arterias. Int J Morphol. 2013; 31 (3): 911-914.

19. Moosa MR. Kidney transplantation in developing countries. In: Morris PJ, Knechtle SJ (ed.). Kidney transplantation: Principles and practice. 7a. ed. Oxford: Elsevier; 2016, pp. 643-675.

20. Watson CJ, Harper SJ. Anatomical variation and its management in transplantation. Am J Transplant. 2015; 15 (6): 1459-1471.

21. Méndez LV, Casado MP, Méndez LH, Ferrer MC, Trevín FG. Variantes anatómicas de las venas renales. Revista Médica Electrónica. 2016; 38 (6): 817-825.

22. Arteaga MM, García PI, Sánchez GC. Desarrollo del Sistema Cardiovascular. En: Arteaga Martínez M, García Peláez MI (ed.). Embriología humana y biología del desarrollo. 2a. ed. Ciudad de México: Médica Panamericana; 2017, pp. 339-396.

23. García LR, Gracida JC, Cedillo U, Jorge CL, Espinoza PR. Variaciones vasculares en el injerto renal y sus resultados en el trasplante renal. Rev Med Inst Mex Seguro Soc. 2010; 48 (2): 193-198.

24. Afriansyah A, Rasyid N, Rodjani A, Wahyudi I, Mochtar CA, Susalit $E$ et al. Laparoscopic procurement of single versus multiple artery kidney allografts: Meta-analysis of comparative studies. Asian J Surg. 2019; 42: 61-70.

25. Lladó C, Fuentes S, Mariano J, Paszkiewicz MR, Massé P, Iriarte G. Angiotomografía renal en el donante vivo y su correlación con la ablación quirúrgica. Revista Argentina de Radiología. 2017; 81 (4): 262-269.

26. Ikidag MA, Uysal E. Evaluation of vascular structures of living donor kidneys by multislice computed tomography angiography before transplant surgery: is arterial phase sufficient for determination of both arteries and veins? J Belg Soc Radiol. 2019; 103 (1): 1-6.

27. Namasivayam S, Small WC, Kalra MK, Torres WE, Newell KA, Mittal PK. Multidetector-row CT angiography for preoperative evaluation of potential laparoscopic renal donors: how accurate are we? Clin Imag. 2006; 30 (2): 120-126.

28. Tyson MD, Castle EP, Ko EY, Andrews PE, Heilman RL, Mekeel $\mathrm{KL}$ et al. Living donor kidney transplantation with multiple renal arteries in the laparoscopic era. Urology. 2011; 77 (5): 11161121.

29. Wang K, Zhang P, Xu X, Fan M. Right versus left laparoscopic living-donor nephrectomy: a meta-analysis. Exp Clin Transplant. 2015; 3: 214-226.

30. Lafranca JA, Van Bruggen M, Kimenai HJ, Tran TC, Terkivatan $T$, Betjes MG et al. Vascular multiplicity should not be a contraIndication for live kidney donation and transplantation. PLOS One. 2016; 11 (4): 1-11.

31. Srivastava A, Bansal A, Sureka SK, Yadav P, Srivastava $D$, Jena $R$ et al. A retrospective analysis of complications of laparoscopic left donor nephrectomy using the Kocak's modification of Clavien-Dindo system. Indian J Urol. 2018; 34 (2): 133-139.

32. Broseta Rico E, Budía Alba A, Gasión Burgués JP, Lujan Marco S. Trasplante renal. En: Broseta Rico E, Budía Alba A, Gasión Burgués JP, Lujan Marco S (ed.). Urología práctica. 4a. ed. Madrid: Elsevier; 2016, pp. 598-607.

33. Zorgdrager M, Krikke C, Hofker SH, Leuvenink HGD, Pol RA. Multiple renal arteries in kidney transplantation: a systematic review and meta-analysis. Ann Transplant. 2016; 21: 469-478.

34. Reyna-Sepúlveda F, Ponce-Escobedo A, Guevara-Charles $A$, Escobedo-Villarreal M, Pérez-Rodríguez E, Hernández- 
Guedea $\mathrm{G}$ et al. Outcomes and surgical complications in kidney transplantation. Int J Organ Transplant Med. 2017; 8 (2): 79-84.

35. Lempinen M, Stenman J, Kyllönen L, Salmela K. Surgical complications following 1670 consecutive adult renal transplantations: A single center study. Scand J Surg. 2015; 104 (4): 254-259.

36. Schiavelli R, Rosés J, Tullio D Di, Gautos A, Sabbatiello R, Raño M. Retraso de la función del injerto en trasplante renal. Nefrología, Diálisis y Trasplante. 2015; 35 (4): 182-187.
37. Jeong EC, Hwang SH, Eo SR. Vascular augmentation in renal transplantation: Supercharging and turbocharging. Arch Plast Surg. 2017; 44 (3): 238-242.

Correspondencia:

Brian Rubio-Marín

E-mail: rubiomarinbrian@gmail.com 